\title{
The Tyr (albino) locus of the laboratory mouse
}

\author{
Friedrich Beermann, ${ }^{1}$ Seth J. Orlow, ${ }^{2}$ M. Lynn Lamoreux ${ }^{3}$ \\ ${ }^{1}$ ISREC (Swiss Institute for Experimental Cancer Research), National Center of Competence in Research (NCCR) \\ Molecular Oncology, Chemin des Boveresses 155, 1066 Epalinges, Switzerland \\ ${ }^{2}$ The Ronald O. Perelman Department of Dermatology \& The Department of Cell Biology, New York University School of Medicine, \\ New York, New York 10016, USA \\ ${ }^{3} 8255$ Sandy Point Road, Bryan, Texas 77807, USA
}

Received: 26 July 2002 / Accepted: 24 May 2004

\begin{abstract}
The albino mouse was already known in ancient times and was apparently selectively bred in Egypt, China, and Japan. Thus, it is not surprising that the $c$ or albino locus (now the Tyr locus) was among the first used to demonstrate Mendelian inheritance in mammals at the dawn of the past century. This locus is now known to encode tyrosinase, the ratelimiting enzyme in the production of melanin pigment, and the molecular basis of the albino $\left(\mathrm{Tyr}^{\mathrm{C}}\right)$ mutation is known. Here we describe the congenic series of Tyr-locus alleles, from wild type to null (albino). We compare eye and skin pigmentation phenotypes and the genetic lesions that cause each. We suggest that this panel of congenic mutants contains rich, untapped resources for the study of many questions of basic cell biological interest.
\end{abstract}

The albino mouse was already known in ancient times and, over a century ago, was used to first demonstrate Mendelian inheritance of a genetic trait in mammals (Castle and Allen 1903). Very early on it was suggested that the albino gene locus was responsible for a "factor" that is necessary for melanin pigment to form in the melanocytes. This "factor" has been identified as tyrosinase, the ratelimiting enzyme for melanogenesis (Coleman 1982). Tyrosinase is encoded at the albino (Tyr) locus of the mouse on Chromosome 7 (Kwon et al. 1989b), where multiple natural mutations and manmade mutations (Fig. 1) have helped to define the functions and

Correspondence to: Friedrich Beermann; E-mail: Friedrich.Beermann@isrec.unil.ch interactions of this enzyme with other proteins that together effect normal pigmentation. In human, the defect in tyrosinase is called oculocutaneous albinism type 1 (OCA1) and is often specified as OCA1A or OCA1B to distinguish between no pigment or less pigment, respectively. The genetic defect in the tyrosinase gene affects the quantity of pigment produced within the melanosome; melanin is absent or reduced, but melanocytes are present in the skin and hair follicles and they contain melanosomes. In addition to effects on pigmentation, albino mice have defects in the visual projections at the optic chiasm (Jeffery et al. 1994), decreased numbers of rod photoreceptors (Donatien and Jeffery 2002; Rachel et al. 2002a), and spatiotemporal defects in neuronal production (Rachel et al. 2002a). Furthermore, a role for tyrosinase in the occurrence of glaucoma by a mechanism apparently unlinked to melanin production has recently been suggested (Libby et al. 2003).

Melanin pigment is produced primarily in two different cell types, the neural crest-derived melanocytes found in skin, hair follicle, and the choroid, ciliary body, and iris of the eye, and the retinal pigment epithelium, a cell layer of the retina that is derived from the optic cup. In the pigment cells, melanin is synthesized and deposited within endolysosome-like organelles, termed "melanosomes," by a series of enzymatic reactions beginning with tyrosine as substrate, and involving the copper-glycoenzyme tyrosinase (Garcia-Borron and Solano 2002). The melanin product is deposited within the melanosome as eumelanic (brown or black) or pheomelanic (yellow/red) pigment. It had long been believed that the first two reactions in the melanogenic pathway-the hydroxylation of tyrosine to dopa (3,4-dihydroxyphenylalanine) and the oxidation of dopa to dopaquinone-are catalyzed by the enzyme tyrosinase (del Marmol and Beermann 1996). 


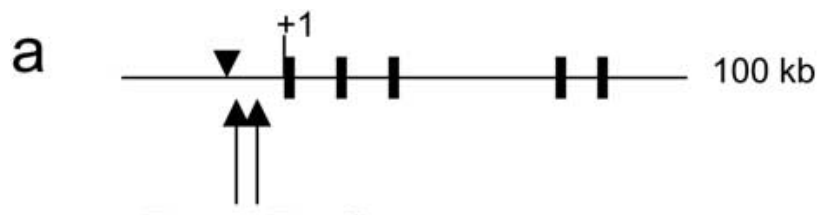

Tyro-m Tyro-1R

Tyro-em
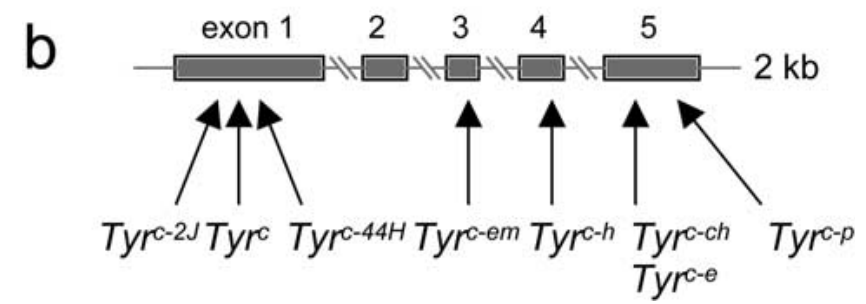

Fig. 1. The mouse tyrosinase gene and location of identified mutations. (a) The Tyr gene locus, showing relative size of introns (Ruppert et al. 1988) and location of the enhancer/dominant control region at $-15 \mathrm{~kb}$ (black arrowhead). The transcription start site is indicated as +1 . (b) Exon/intron structure of the tyrosinase gene and location of mutations which were identified within coding sequence. Note that $\mathrm{Tyr}^{\mathrm{c}-\mathrm{em}}$ is listed twice since it appeared on a $\mathrm{Tyr}^{\mathrm{c}-m}$ background.

More recent chemical analyses have suggested, however, that tyrosinase-catalyzed oxidation of tyrosine leads directly to dopaquinone, which then can lead to eumelanin formation via spontaneous formation of dopachrome (Wakamatsu and Ito 2002). Accordingly, dopa itself can act as a cofactor in tyrosine oxidation and is not derived by tyrosinase enzyme activity, but indirectly by reduction of dopaquinone (Riley 1999). The pheomelanic pathway is thought to be initiated by a reaction between cysteine and dopaquinone, thus leading to cysteinyldopa, and further to benzothiazoles. Accordingly, the balance between pheomelanin and eumelanin may be determined by the availability of cysteine as precursor (Land and Riley 2000).

Besides tyrosinase, two other enzymes function in melanogenesis, dopachrome tautomerase (DCT) and tyrosinase-related protein 1 (TYRP1). DCT is encoded at the slaty (now Dct) locus of the mouse, and TYRP1 is encoded at the black/brown (now Tyrp1) locus. When all three of these enzymes function normally, eumelanin pigment is deposited within the melanosome (Fig. 2). Analysis of mice that are mutant at the Tyr or Tyrp1 locus has shown that mutation in one may affect the phenotype associated with the other. Accordingly, TYRP1 may affect stability of tyrosinase (Manga et al. 2000), and both proteins are transported together from the endoplasmic reticulum to the melanosome (Toyof-

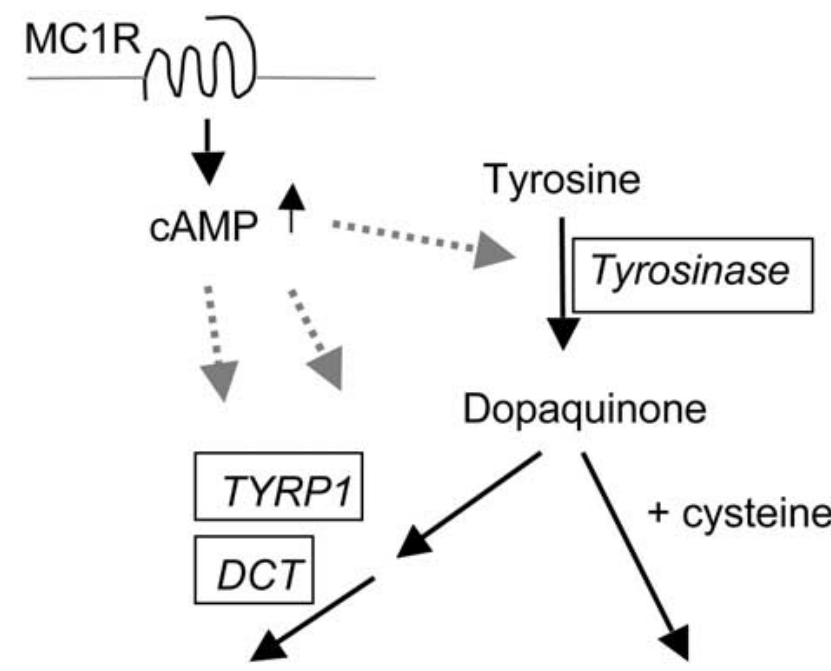

Eumelanin
(black/brown)

Pheomelanin (red/yellow)

Fig. 2. Scheme of melanin synthesis. Activation of melanocortin receptor 1 (MC1R) increases cAMP levels, thus enhancing tyrosinase activity and favoring eumelanin synthesis (del Marmol and Beermann 1996; Barsh 2003). Tyrosinase-related protein 1 (TYRP1) and dopachrome tautomerase (DCT) are enzymes of eumelanin synthesis only.

uku et al. 2001). Mice lacking Tyrp1 [Tyrp1 deletions (Rinchik et al. 1994)] or Dct [Dct knockout (Guyonneau et al. 2004)] are only slightly affected in pigmentation and show a rather brown (Tyrp1 deficiency) or dark gray (Dct deficiency) coat color. Several other gene loci function within the melanosome and are necessary for normal pigmentation but have not been shown to be so intimately interactive with tyrosinase protein (Bennett and Lamoreux 2003). These loci include pink-eyed dilution ( $p$, mutation causing OCA2 in human) (Chiu et al. 1993), underwhite (uw, now Matp, mutation causing OCA4 in human) (Newton et al. 2001; Costin et al. 2003), and MITF (Mitf) that modulates the expression of a number of melanocyte-specific genes, including Tyr and Tyrp1, at the transcriptional level and influences the eumelanin/pheomelanin switch (Goding 2000; Widlund and Fisher 2003).

Eumelanin (which is black or brown depending upon the genotype at the Tyrp 1 locus) is produced in the melanosome as a result of the normal activity of the MSH (melanocyte stimulating hormone) receptor, which regulates levels of cyclic AMP (cAMP) within the cell and is present in melanocyte cell membranes (Fig. 2). The MSH receptor (MC1R) is encoded at the melanocortin-1 receptor (Mc1r) locus [formerly extension (e) locus] in the mouse and is 
responsive to the environment of the hair follicle in which the melanocyte resides. It is thus capable of switching from an active state that raises cAMP levels and results in the production of eumelanin within the melanosomes of the cell to an inactive state, when pheomelanin is produced (Barsh 2003). In the eumelanic state, elevated cAMP levels are followed by an increase in activity of tyrosinase, DCT, and TYRP1. In the pheomelanic state, the melanosomes produce yellow-colored melanin, cAMP levels are reduced, tyrosinase activity is lower, and DCT and TYRP1 activities are absent (Lamoreux et al. 1995). Mutation at Mc1r can result in melanocortin receptors that are not responsive to the environment and are constitutively active, resulting in production of only eumelanin, as in the sombre $\left(M c 1 r^{E-s O}\right)$ mutant, or constitutively inactive, resulting primarily in the production of pheomelanin as in the hair follicles of the yellow mutant $\left(M c 1 r^{e}\right)$ mouse. Tyrosinase is required for both types of pigment, but activity is reduced in pheomelanic melanocytes. Wild-type MC1R is active unless blocked by the protein encoded at the agouti locus, thus switching pigment synthesis from the eumelanin pathway toward the pheomelanin pathway (Barsh 2003). Thus, mice that are yellow because of mutation at the agouti locus continue to produce the agouti-locus protein inappropriately and do not switch back and forth from the production of eumelanin to the production of pheomelanin as is normal in wild-type agouti mice. In addition, several other pigment loci encode proteins that interact with the Mclr/agouti protein switch mechanism. These include mahogany (Atrn) and mahoganoid, both of which result in a reduction of pheomelanin, or rather an increase in eumelanin, in the hair coats of mutant mice (He et al. 2003). Interestingly, the Tyr-locus mutants (except for platinum) preferentially reduce the amount of pheomelanin compared with the reduction in eumelanin. Hence, the impact of Tyr-locus mutations is greater in pheomelanic mice than in eumelanic mice (Lamoreux and Pendergast 1987; Lamoreux et al. 2001) and also in pheomelanic locations on a mouse as for example the belly.

Availability of multiple mouse Tyr (albino) locus alleles with various sorts of genetic lesions provides an opportunity to evaluate the dynamic interactions in the processes that intervene between the transcription of the tyrosinase gene and the resulting phenotype of the animal. These include transcription, translation, post-translational processing, and transport mechanisms, as well as interactions with the products of other loci. Moreover, many other mutations causing albinism act via tyrosinase by affecting tyrosinase processing [e.g., pink-eyed dilution (Chen et al. 2002)] or tyrosinase trafficking [e.g., forms of Hermansky-Pudlak syndrome (Huizing et al. 2002)]. In this review, we report on the current state of knowledge regarding the molecular bases and phenotypic consequences of mutations at the mouse Tyr (albino) gene locus (Fig. 3, Table 1).

\section{The allelic series}

In the absence of mutations at other loci, mice that are wild type at the Tyr locus are fully pigmented and are black $(T y r+/ T y r+, a / a)$. Wild type is dominant to all other alleles at the locus, though one semidominant mutant (albino-strong, $\mathrm{Tyr}^{c-s}$ ) is reported at the JAX web site (http://www.informatics.jax.org/searches/mlc.cgi?14347). Mice that are lacking the Tyr locus as a result of overlapping deletions $\left(\mathrm{Tyr}^{\mathrm{c}-6 \mathrm{H}}\right)$ $\mathrm{Tyr}^{\mathrm{c}-14 \mathrm{CoS}}$ ) are unpigmented, although melanosomes are present, confirming the requirement of the Tyr locus and a functional tyrosinase for pigment production (Russell et al. 1982; Rinchik et al. 1993). Similarly, two natural mutations have been identified that result in an albino phenotype associated with lack of tyrosinase activity, $\operatorname{Tyr}^{c}$ and $\operatorname{Tyr}^{c-2 J}$. The classic mouse albino mutation, $\mathrm{Tyr}^{c}$, which is present in common albino mouse strains such as BALB/c or $\mathrm{FVB}$, is characterized by the complete absence of pigmentation in both skin and eyes and by aberrant decussation of the optic nerve at the level of the chiasm (Guillery 1974; LaVail et al. 1978). Even though tissue homogenates of BALB/c mice might retain a slight amount of tyrosinase-dependent melanin synthesis in vitro (Hearing 1973), $\mathrm{Tyr}^{\mathrm{c}}$ is considered a null mutation since the mutated protein is not active in vivo and is retained in the ER (Halaban et al. 2000; Toyofuku et al. 2001). The molecular change in $\mathrm{Tyr}^{c}$ is a G-to-C mutation at position +387 , which results in the substitution of a cysteine for a serine residue at position 103 (Kwon et al. 1989b; Shibahara et al. 1990; Yokoyama et al. 1990). The $\mathrm{Tyr}^{\mathrm{c}-2 \mathrm{~J}}$ mutation arose spontaneously in C57BL/6J mice, and homozygous $\mathrm{Tyr}^{c-2 I} / \mathrm{Tyr}^{c-2 I}$ mice are phenotypically identical to $\mathrm{Tyr}^{c} / \mathrm{Tyr}^{c}$ mice. The mutation was identified as a G-to-T change at position +309 , resulting in an arginine-to-leucine substitution at codon 77 and furthermore led to increased alternative splicing within exon 1 (Lefur et al. 1996, 1997). Enzymatic activity of tyrosinase is absent in normal melanocytes of these mice, but melanomas occurring on this $\mathrm{Tyr}^{\mathrm{c}-2 J}$ genetic background can be pigmented and are tyrosinase positive (Cohen-Solal et al. 2002), in contrast to melanomas appearing on BALB/c or FVB mice $\left(T y r^{c}\right)$ (Cohen-Solal et al. 2001). Thus, it is 
Table 1. Phenotype and molecular lesion of selected Tyr locus alleles

\begin{tabular}{|c|c|c|}
\hline Pigment phenotype & Allele & Molecular lesion \\
\hline \multicolumn{3}{|c|}{ Eyes and hair similarly pigmented/affected: } \\
\hline Fully pigmented & Tyr+, wildtype & \\
\hline No pigment, albino & $\operatorname{Tyr}^{c^{-6 H}} / \operatorname{Tyr}^{\mathrm{c}^{-14}}$ & Tyrosinase deletion \\
\hline & Tyr ${ }^{c}$ (albino) & C103S \\
\hline & Tyr $^{c-2 I}$ (albino) & R77L \\
\hline Dark gray, black eye & Tyr $r^{-c h}$ (chinchilla) & $\mathrm{A} 482 \mathrm{~T}$ \\
\hline Pale coat, pink eye & $\operatorname{Tyr}^{c-p}$ (platinum) & K507STOP \\
\hline \multicolumn{3}{|l|}{ Eyes more pigmented than hair: } \\
\hline Mid gray, dark eye & $\operatorname{Tyr}^{c-e}$ (extreme dilution) & A482T (additional mutation?) \\
\hline Extremities pigmented, dark eye & Tyr $^{c-h}$ (himalayan) & H420R \\
\hline & $\mathrm{Tyr}^{c-a}$ (acromelanic) & No protein detected, RNA low \\
\hline Albino, dark eye & Tyr $^{c-44 H}$ (dark eyed albino) & S146I \\
\hline \multicolumn{3}{|l|}{ Mottled: } \\
\hline Mottled coat and eye & $\begin{array}{l}\text { Tyr } r^{c-m} \text { (chinchilla mottled) } \\
\left.T^{c-e m} \text { (extreme dilution mottled }\right) \\
\text {Tyr}^{c-1 R}\end{array}$ & $\begin{array}{l}\text { Rearrangement in } 5^{\prime} \text { region } \\
\text { Rearrangement in } 5^{\prime} \text { region T373I } \\
\text { IAP element insertion at promoter }\end{array}$ \\
\hline
\end{tabular}

See text for references and further details. Numbering of nucleotides and amino acids varied in the past, depending upon the definition of the start site and upon whether the signal peptide was included. In this article we refer to the published transcriptional start site $(+1)$ (Bentley et al. 1994). For the amino acid sequence, the start codon (ATG) is counted as +1 .

tracts of platinum mice, a large proportion of tyrosinase is present in soluble form (Townsend et al. 1981). Furthermore, phenotypic differences in intensity of pigmentation between pheomelanic and eumelanic platinum mice are not evident, and both appear equally pale. These differences between platinum and chinchilla mice suggested that tyrosinase is functional in platinum mice, as the tyrosinase activities of skin and eyes are higher than those of chinchilla mice, which have lower tyrosinase activity but much more intense pigmentation. In addition, the effect of pheomelanogenesis on tyrosinase activity is sidestepped in the case of platinum mice. Analysis of the tyrosinase protein suggested a mutation at the carboxy terminal part of the protein (Orlow et al. 1993), and electron microscope studies demonstrated tyrosinase activity in the trans-Golgi network and in nearby vesicles, but missing activity in melanosomes (Beermann et al. 1995). Instead, tyrosinase was found at the cell surface. Since melanogenesis is confined essentially to the melanosome, it is thus reasonable not to detect major differences between pheo- and eumelanogenesis in this specific mutant allele. The mutation in platinum is a G-to-A change at +1523 (Beermann et al. 1995), inferring a replacement of a lysine residue in the cytoplasmic tail by a termination codon. The lack of the cytoplasmic tail, which contains the essential di-leucine sorting motif, is causing misrouting of platinum tyrosinase to the cell surface (Beermann et al. 1995; Simmen et al. 1999).

Second, there are alleles with more effect on coat pigmentation, e.g., extreme dilution $\left(\mathrm{Tyr}^{\mathrm{c}-e}\right)$. The original $\mathrm{Tyr}^{\mathrm{c}-\mathrm{e}}$-mutation was found in the wild (Detlefsen 1921). C57BL/6J mice that are homozygous at this locus can be characterized as "midgray" in phenotype, more or less midway in intensity between wild type and albino but with eyes that are nearer to black. Both tyrosinase activity and amount of eumelanin are greatly reduced in C57BL/6J-Tyr $r^{c-e} / \mathrm{Tyr}^{c-}$ ${ }^{e}$ mice; melanosomes of $\mathrm{Tyr}^{\mathrm{c}-e} / \mathrm{Tyr}^{\mathrm{c}-e}$ are reduced in both number and size (Markert and Silvers 1956; Moyer 1966). Northern blot analysis of newborns' skins (not shown) showed no reduction in abundance of tyrosinase mRNA in $\mathrm{Tyr}^{c-e} / \mathrm{Tyr}^{c-e}$ mice that are eumelanic. Sequencing the complete coding region demonstrated a deviation from wild type in exon 5, leading to exchange of an alanine by a threonine, the very same mutation (A482T) that had been identified in the chinchilla $\left(\mathrm{Tyr}^{c-c h}\right)$ mutation (Beermann et al. 1990). A482T is the only mutation found in the coding sequence of the chinchilla $\left(\mathrm{Tyr}^{\mathrm{c}-\mathrm{ch}}\right)$ tyrosinase gene; it affects tyrosinase in vivo (Halaban et al. 1988) and following transfections (unpublished data). Therefore, it is rather unlikely that $\mathrm{A} 482 \mathrm{~T}$ is a polymorphism, with two unidentifed mutations still existing for both chinchilla and extreme dilution. It is more likely that the $\mathrm{Tyr}^{c-e}$ mutation may have occurred on a Tyr ${ }^{c-c h}$ background and might contain a yet unidentified second mutation, for example, in the regulatory region.

Himalayan is a spontaneous mutation which occurred in offspring of a cross between DBA/ 2 and AKR/J (Green 1961). Mice homozygous for the himalayan mutation $\left(\mathrm{Tyr}^{\mathrm{c}-h}\right)$, similar to himalayan cats or rabbits, over time develop more intense pigmentation at the extremities where the body is cooler. Their body color is beige, with darker-beige extremities, and eyes are dark ruby. The mutation is an A-to-G change at nucleotide 1338 that alters 
a histidine residue to an arginine residue at amino acid 420 (Kwon et al. 1989a). The activity of tyrosinase isolated from skins of $\mathrm{Tyr}^{c-h} / \mathrm{Tyr}^{c-h}$ mice is heat labile (Coleman 1962), but the protein itself has been reported not to be heat-sensitive (Townsend et al. 1985), and it has been stated that the himalayan tyrosinase binds an inhibitor differentially at different temperatures (Kidson and Fabian 1981). A similar mutation in human (Giebel et al. 1991), which is located only two codons away, results in a thermosensitive protein upon transfection into HeLa cells. Thus, the himalayan $\left(\mathrm{Tyr}^{c-h}\right)$ $\left.\mathrm{Tyr}^{c-h}\right)$ mouse would seem to be an excellent model for the condition in man and deserves further study to understand the cause of this thermosensitivity.

Acromelanic $\left(\mathrm{Tyr}^{\mathrm{c}-a}\right)$ is a spontaneous mutation which occurred on the $\mathrm{C} 3 \mathrm{H} / \mathrm{HeJ}$ strain (Sweet 1987). Acromelanic mice are beige in coat color (similar to himalayan) but have dark eyes and pigment appearing on tail, ears, and extremities. We sequenced the complete coding sequence, including about $270 \mathrm{bp}$ upstream of the transcription start site, and no change to the wild-type tyrosinase sequence was detected. This result is in accordance with failure to detect protein and message on Western blots (not shown) and Northern blots (not shown). The message was nevertheless detectable by RT-PCR (not shown), thus suggesting a defect in transcriptional regulation or RNA stability. No major rearrangements were detected by Southern blot analysis covering about $15 \mathrm{~kb}$ of tyrosinase $5^{\prime}$ sequence (not shown). Since the mutation affects RNA levels, three unsequenced areas remain to be tested for the presence of mutation: (1) the enhancer region (Ganss et al. 1994; Porter and Meyer 1994), (2) the 3' noncoding sequences which might be involved in tyrosinase regulation and mRNA stability (Takeuchi et al. 2000), and (3) the exon/ intron boundaries, which might affect the correct splicing (Ruppert et al. 1988; Lefur et al. 1997). A defect in the enhancer region might explain the different effect in skin melanocytes versus RPE pigmentation by affecting regulation preferentially in either cell type (Porter et al. 1999; CamachoHübner and Beermann 2001). On the other hand, the choroidal layer, which equally consists of neural crest-derived melanocytes, is pigmented in acromelanic mice. Thus, it might rather be the steady accumulation of low levels of melanin within the RPE (and the choroidal layer) that makes the eye pigmented but keeps the skin and hair rather unpigmented. In addition, the presence of pigment at the extremities might point to a certain temperature-sensitive effect. How this is explained without an obvious mutation in the cDNA remains to be discovered.

In homozygous dark-eyed albino $\left(\mathrm{Tyr}^{\mathrm{c}-44 H}\right)$ mice, overall pigment production is greatly reduced and is obvious only in the eyes (Cattanach and Rasberry 1988). Dark-eyed-albino mice are born white with ruby-colored eyes, which darken to become almost black by 3-4 months of age. The hair coat, by contrast, remains essentially unpigmented. Enzymatic activity of tyrosinase and melanin levels in the retina of $\mathrm{Tyr}^{\mathrm{c}-44 \mathrm{H}} / \mathrm{Tyr}^{\mathrm{c}-44 \mathrm{H}}$ newborn mice reached levels of only $2.6 \%$ (tyrosinase activity) and $11.8 \%$ (melanin) of wild type (Rachel et al. 2002b). By Southern blot, Northern blot, and RT-PCR analyses, it was demonstrated that the basis of the phenotype resides in the coding sequences, with a point mutation (Gto- $\mathrm{T}$ ) in exon 1 , at position +515 , inferring a substitution of the amino acid serine by isoleucine (position +146$)$ (Schmidt and Beermann 1994).

Third, alleles exist that depict a mottled or variegated coat color $\left(\operatorname{Tyr}^{c-m}, \mathrm{Tyr}^{c-1 R}, \mathrm{Tyr}^{c-e m}\right)$. Mice carrying the chinchilla-mottled mutation $\left(\mathrm{Tyr}^{\mathrm{c}-\mathrm{m}}\right)$ were found in the offspring of a neutron-irradiated male (Phillips 1970), and $\mathrm{Tyr}^{\mathrm{c}-1 R}$ arose spontaneously in 1988 in the Oak Ridge National Laboratory in a C3Hf/RI strain (Wu et al. 1997). Northern blot analyses and RT-PCR data showed that expression of tyrosinase is significantly diminished in homozygous $\mathrm{Tyr}^{\mathrm{c}-1 R}$ mutant mice when compared with wild-type controls (Wu et al. 1997). Both $\mathrm{Tyr}^{c-m}$ and $\mathrm{Tyr}^{\mathrm{c}-1 R}$ cause a phenotype of mottled pigmentation resembling a chimerism of chinchilla color and a paler shade in homozygous mice. In $T y r^{c-m}$, which exhibit dark and light gray stripes on the coat, the mottled pigmentation is due to differential tyrosinase gene expression and changed chromatin structure of the Tyr gene locus in melanocytes within a stripe (Porter et al. 1991). This inherited mottling, as seen also in some tyrosinase-transgenic mice, results from the formation of phenotypically different but genetically identical developmental clones among cells of the same type (Bradl et al. 1991). Eyes of Tyr ${ }^{C^{-}}$ $\mathrm{m} / \mathrm{Tyr}^{\mathrm{c}-\mathrm{m}}$ mice appear dark, and older findings indicate that they are chimeric, with patches of darker and lighter pigmented cells (Deol and Truslove 1980). Molecular analysis of $\mathrm{Tyr}^{c-m} / \mathrm{Tyr}^{c-m}$ DNA demonstrated a normal coding region but a major rearrangement involving $30 \mathrm{~kb}$ of $5^{\prime}$ upstream tyrosinase regulatory sequences, including the locus control region (Porter et al. 1991; Porter and Meyer 1994; Lavado Judez and Montoliu 2002). Molecular analysis of $\mathrm{Tyr}^{\mathrm{c}-1 R}$ revealed insertion of a $5.4-\mathrm{kb}$ intracisternal A particle (IAP) element at $-225 \mathrm{bp}$ upstream of the tyrosinase promoter (Wu et al. 1997). Thus, this IAP element isolates the promoter of the 
tyrosinase gene from the upstream tyrosinase locus control region, thereby either increasing the distance between this enhancer and the promoter or directly negatively affecting tyrosinase gene expression. The tyrosinase locus control region, which equally exists in human tyrosinase (Fryer et al. 2003; Regales et al. 2003), has recently been shown to have boundary activity, protecting the tyrosinase gene regulation from negative effects of neighboring chromatin (Giraldo et al. 2003). Thus, in the case of the mottled mutations, it is feasible that (1) the boundary activity cannot be exerted, (2) the new introduced sequences result in novel "negative" influences as hypermethylation, and (3) interaction of the enhancer sequences with promoter sequences such as the MITF binding site is affected. A third mottled mutation, extreme-dilution mottled $\left(\mathrm{Tyr}^{\mathrm{c}-\mathrm{em}}\right)$, arose spontaneously in Harwell (UK) in breeding chinchilla mottled mice $\left(\mathrm{Tyr}^{\mathrm{c}-\mathrm{m}}\right)$. Homozygotes for this allele possess black eyes and light gray fur that is variegated. The molecular basis of this mutation has been identified, on top of the rearrangements inherent in the mottled stock ( $\mathrm{Tyr}^{\mathrm{c}-\mathrm{m}}$, see above), as a point mutation ( $\mathrm{C}$ to $\mathrm{T}$ ) in exon 3 of tyrosinase at position $+1197(+1220$ according to the numbering of the authors), implying a substitution of the amino acid threonine by isoleucine (position +373 ) (Lavado Judez and Montoliu 2002).

\section{Conclusion}

We have reviewed and described alleles at the Tyr locus in the mouse and have added some new information. Most mice congenic with C57BL/6J should soon be available and thus offer a unique resource for the study of genic action and interactions. Regarding pigmentation of the albino series, it is striking that effects on eye and fur pigmentation seem to differ. This might be due to transfer of melanosomes from neural crest-derived melanocytes in skin and hair follicles, whereas they are retained in the retinal pigment epithelial cells and the choroidal melanocytes. This is exemplified by recent analyses on the $\mathrm{Tyr}^{\mathrm{c}-44 \mathrm{H}}$ (dark-eyed albino) allele, where tyrosinase activities in the retina of homozygotes at birth were much more reduced $(2.6 \%)$ compared with the melanin levels $(11.8 \%$ of wild type) (Rachel et al. 2002b). Alternatively, there might exist differences in tyrosinase gene expression between the two cell types. Initial experiments by Porter and Meyer (1994) had indicated that the enhancer region (dominant control region) of the mouse tyrosinase gene could be a candidate for such a differential regulation. The presence of the enhancer increased melanin deposition primarily in the neural crest cells (e.g., iris) but not to the same degree in cells of the retinal pigment epithelium (Porter and Meyer 1994). This observation was confirmed later using transgenic mice and transfection experiments (Porter et al. 1999; Camacho-Hübner and Beermann 2001), suggesting that there might be a differential regulation between optic cup-derived and neural crest-derived pigment cells.

Several of the mutants at the Tyr locus indirectly affect phenotypes associated with other loci. For example, brown (TYRP1) protein and tyrosinase protein interact rather closely to produce the pigment phenotype. A chinchilla mutant (Tyr ${ }^{c-c h}$ ) mouse that is black (Tyrp1+) exhibits a slight but visible reduction in pigment intensity. In contrast, the difference between a brown $\left(\operatorname{Tyrp}_{1} 1^{b}\right)$ mouse and a brown chinchilla mutant (Tyrp $\left.1^{b}, T_{y r}{ }^{c-c h}\right)$ mouse is not obvious. It has been shown that tyrosinase-negative albinism, at least in some instances, is an ERretention disease, with tyrosinase retained in the ER, which also affects localization of TYRP1 (Toyofuku et al. 2001). The availability of multiple alleles at this Tyr gene locus which is essential for pigmentation and retinal development but dispensable for survival, and which contains various genetic lesions, provides an opportunity to evaluate the dynamic interactions in the processes that intervene between the transcription of the tyrosinase gene and the resulting phenotype of the animal. This rich source of mutations has allowed and will allow studies to address various cellular mechanisms ranging from defects in transcriptional regulation to protein mislocalization and retinal development/organization.

\section{Acknowledgments}

Thanks are due to Andrea Schmidt for help with the DNA and RNA analyses of $\mathrm{Tyr}^{\mathrm{c}-e}$ and $\mathrm{Tyr}^{\mathrm{c}-a}$ mutant mice. Work in the laboratory of FB was supported by grants from the Swiss Cancer League, by grant 3100 066796.01 from the Swiss National Science Foundation, and by the National Center of Competence in Research (NCCR) Molecular Oncology, a research instrument of the Swiss National Science Foundation, and in the laboratory of SJO by PHS grants EY10223 and AR41880.

\section{References}

1. Barsh G (2003) What controls variation in human skin color? PLoS Biol 1, 019-022

2. Beermann F, Ruppert S, Hummler E, Bosch FX, Müller G, et al. (1990) Rescue of the albino phenotype by introduction of a functional tyrosinase gene into mice. EMBO J 9, 2819-2826 
3. Beermann F, Orlow SI, Boissy RE, Schmidt A, Boissy YL, et al. (1995) Misrouting of tyrosinase with a truncated cytoplasmic tail as a result of the murine platinum (cp) mutation. Exp Eye Res 61, 599-607

4. Bennett D, Lamoreux M (2003) The color loci of mice -a genetic century. Pigment Cell Res 16, 333-344

5. Bentley NJ, Eisen T, Goding CR (1994) Melanocytespecific expression of the human tyrosinase promoter: activation by the microphthalmia gene product and role of the initiator. Mol Cell Biol 14, 7996-8006

6. Bradl M, Larue L, Mintz B (1991) Clonal coat color variation due to a transforming gene expressed in melanocytes of transgenic mice. Proc Natl Acad Sci USA 88, 6447-6451

7. Camacho-Hübner A, Beermann F (2001) Increased transgene expresssion by the mouse tyrosinase enhancer is restricted to neural crest-derived pigment cells. Genesis 29, 180-187

8. Castle W, Allen G (1903) The heredity of albinism. Proc Am Acad Arts Sci 38, 603-621

9. Cattanach B, Rasberry C (1988) Dark-eyed albinism. Mouse News Lett 81, 64

10. Chen K, Manga P, Orlow S (2002) Pink-eyed dilution protein controls the processing of tyrosinase. Mol Biol Cell 13, 1953-1964

11. Chiu E, Lamoreux M, Orlow S (1993) Postnatal ocular expression of tyrosinase and related proteins: disruption by the Pink-eyed Unstable (pun) mutation. Exp Eye Res 57, 301-305

12. Cohen-Solal K, Reuhl K, Ryan K, Roberts K, Chen S (2001) Development of cutaneous amelanotic melanoma in the absence of a functional tyrosinase. Pigment Cell Res 14, 466-474

13. Cohen-Solal K, Crespo-Carbone S, Namkoong J, Mackason K, Roberts K, et al. (2002) Progressive appearance of pigmentation in amelanotic melanoma lesions. Pigment Cell Res 15, 282-289

14. Coleman D (1962) Effect of genic substitution on the incorporation of tyrosine into the melanin of the mouse skin. Arch Biochem Biophys 96, 562-568

15. Costin G, Valencia J, Vieira W, Lamoreux M, Hearing V (2003) Tyrosinase processing and intracellular trafficking is disrupted in mouse primary melanocytes carrying the underwhite (uw) mutation. A model for oculocutaneous albinism (OCA) type 4. J Cell Sci 116, 3203-3212

16. del Marmol V, Beermann F (1996) Tyrosinase and related proteins in mammalian pigmentation. FEBS Lett 381, 165-168

17. Deol M, Truslove G (1980) Nonrandom distribution of unpigmented melanocytes in the retina of chinchillamottled mice and its significance. Proc XIth Int Pigment Cell Conf, Sendai, Japan, pp 153-157

18. Detlefsen J (1921) A new mutation in the house mouse. Am Naturalist 55, 469-473

19. Dickie M (1966) Platinum. Mouse News Lett 34, 30

20. Donatien P, Jeffery G (2002) Correlation between rod photoreceptor numbers and levels of ocular pigmentation. Invest Ophthalmol Vis Sci 43, 1198-1203

21. Feldman $H$ (1922) A fourth allelomorph in the albino series of mice. Am Naturalist 56, 573-574
22. Fryer J, Oetting W, King R (2003) Identification and characterization of a DNase hypersensitive region of the human tyrosinase gene. Pigment Cell Res 16, 679684

23. Ganss R, Montoliu L, Monaghan A, Schütz G (1994) A cell-specific enhancer far upstream of the mouse tyrosinase gene confers high level and copy numberrelated expression in transgenic mice. EMBO J 13, 3083-3093

24. Garcia-Borron J, Solano F (2002) Molecular anatomy of tyrosinase and its related proteins: beyond the histidine-bound metal catalytic center. Pigment Cell Res $15,162-173$

25. Giebel LB, Tripathi RK, King RA, Spritz RA (1991) A tyrosinase gene missense mutation in temperaturesensitive type I oculocutaneous albinism. A human homologue to the Siamese cat and the Himalayan mouse. J Clin Invest 87, 1119-1122

26. Giraldo P, Martinez A, Regales L, Lavado A, GarciaDiaz A, et al. (2003) Functional dissection of the mouse tyrosinase locus control region identifies a new putative boundary activity. Nucleic Acids Res 31, 6290-6305

27. Goding C (2000) Mitf from neural crest to melanoma: signal transduction and transcription in the melanocyte lineage. Genes Dev 14, 1712-1728

28. Green M (1961) Himalayan, a new allele of albino in the mouse. J Hered 52, 73-75

29. Grüneberg H (1952) Genetics of the Mouse (The Hague: Nijhoff)

30. Guillery R (1974) Visual pathways in albinos. Sci Am $230,44-54$

31. Guyonneau L, Murisier F, Rossier A, Moulin A, Beermann $F(2004)$ Melanocytes and pigmentation are affected in Dopachrome tautomerase knockout mice. Mol Cell Biol 24, 3396-3403

32. Halaban R, Moellmann G, Tamura A, Kwon B, Kuklinska E, et al. (1988) Tyrosinases of murine melanocytes with mutations at the albino locus. Proc Natl Acad Sci USA 85, 7241-7245

33. Halaban R, Svedine S, Cheng E, Smicun Y, Aron R, et al. (2000) Endoplasmic reticulum retention is a common defect associated with tyrosinase-negative albinism. Proc Natl Acad Sci USA 97, 5889-5894

34. He L, Eldridge A, Jackson P, Gunn T, Barsh G (2003) Accessory proteins for melanocortin signaling: attractin and mahogunin. Ann NY Acad Sci 994, 288-298

35. Hearing V (1973) Tyrosinase activity in subcellular fractions of black and albino mice. Nat New Biol 245, 81-83

36. Huizing M, Boissy R, Gahl W (2000) HermanskyPudlak syndrome: vesicle formation from yeast to man. Pigment Cell Res 15, 405-419

37. Jeffery G, Schütz G, Montoliu L (1994) Correction of abnormal retinal pathways found with albinism by introduction of a functional tyrosinase gene in transgenic mice. Dev Biol 166, 460-464

38. Kidson S, Fabian B (1981) The effect of temperature on tyrosinase activity in himalayan mouse skin. J Exp Zool 215, 91-97 
39. Kwon B, Halaban R, Chintamaneni C (1989a) Molecular basis of mouse himalayan mutation. Biochem Biophys Res Commun 161, 252-260

40. Kwon B, Haq A, Wakulchik M, Kestler D, Barton D, et al. (1989b) Isolation, chromosomal mapping and expression of the mouse tyrosinase gene. J Invest Dermatol 93, 589-594

41. Lamoreux M, Pendergast P (1987) Genetic controls over melanocyte differentiation: interaction of agoutilocus and albino-locus genetic defects. J Exp Zool 243, 71-79

42. Lamoreux M, Zhou B, Rosemblat S, Orlow S (1995) The pinkeyed-dilution protein and the eumelanin/ pheomelanin switch: in support of a unifying hypothesis. Pigment Cell Res 8, 263-270

43. Lamoreux M, Wakamatsu K, Ito S (2001) Interaction of major coat color gene functions in mice as studied by chemical analysis of eumelanin and pheomelanin. Pigment Cell Res 14, 23-31

44. Land E, Riley P (2000) Spontaneous redox reactions of dopaquinone and the balance between the eumelanic and phaeomelanic pathway. Pigment Cell Res 13, 273277

45. Lavado Judez A, Montoliu L (2002) Histological, enzymatic and molecular analysis of chinchilla-mottled $\left(\mathrm{Tyr}^{\mathrm{c}-\mathrm{m}}\right)$ and extreme dilution mottled $\left(\mathrm{Tyr}^{\mathrm{c}-\mathrm{em}}\right)$ mouse mutant tyrosinase alleles. Pigment Cell Res 15 Suppl 9, 63(abstract)

46. La Vail J, Nixon R, Sidman R (1978) Genetic control of retinal ganglion cell projections. J Comp Neurol 182, 399-421

47. Lefur N, Kelsall SR, Mintz B (1996) Base substitution at different alternative splice donor sites of the tyrosinase gene in murine albinism. Genomics 37, 245-248

48. Lefur N, Kelsall SR, Silvers WK, Mintz B (1997) Selective increase in specific alternative splice variants of tyrosinase in murine melanomas - a projected basis for immunotherapy. Proc Natl Acad Sci USA 94, 5332-5337

49. Libby R, Smith R, Savinova O, Zabaleta A, Martin J, et al. (2003) Modification of ocular defects in mouse developmental glaucoma models by tyrosinase. Science 299, 1578-1581

50. Manga P, Sato K, Ye L, Beermann F, Lamoreux M, et al. (2000) Mutational analysis of the modulation of tyrosinase by tyrosinase-related proteins 1 and 2 in vitro. Pigment Cell Res 13, 364-374

51. Markert C, Silvers W (1956) The effects of genotype and cell environment on melanoblast differentiation in the house mouse. Genetics 41, 429-450

52. Moyer F (1966) Genetic variations in the fine structure and ontogeny of mouse melanin granules. Am Zool 6, 43-66

53. Newton J, Cohen-Barak O, Hagiwara N, Gardner J, Davisson M, et al. (2001) Mutations in the human orthologue of the mouse underwhite gene (uw) underlie a new form of oculocutaneous albinism, OCA4. Am J Hum Genet 69, 981-988

54. Orlow SJ, Boissy RE, Moran DJ, Pifko-Hirst S (1993) Subcellular distribution of tyrosinase and tyrosinase- related protein-1: implications for melanosomal biogenesis. J Invest Dermatol 100, 55-64

55. Phillips R (1970) Chinchilla-mottled. Mouse News Lett 42,26

56. Porter SD, Meyer CJ (1994) A distal tyrosinase upstream element stimulates gene expression in neuralcrest-derived melanocytes of transgenic mice: position-independent and mosaic expression. Development 120, 2103-2111

57. Porter S, Larue L, Mintz B (1991) Mosaicism of tyrosinase-locus transcription and chromatin structure in dark vs. light melanocyte clones of homozygous chinchilla-mottled mice. Dev Genet 12, 393-402

58. Porter S, Hu J, Gilks C (1999) Distal upstream tyrosinase S/MAR-containing sequence has regulatory properties specific to subsets of melanocytes. Dev Genet 25, 40-48

59. Rachel R, Dolen G, Hayes N, Lu A, Erskine L, et al. (2002a) Spatiotemporal features of early neurogenesis differ in wild-type and albino mouse retina. J Neurosci 22, 4249-4263

60. Rachel R, Mason C, Beermann F (2002b) Influence of tyrosinase levels on pigment accumulation in the retinal pigment epithelium and on the uncrossed retinal projection. Pigment Cell Res 15, 273-281

61. Regales L, Giraldo P, Garcia-Diaz A, Lavado A, Montoliu L (2003) Identification and functional validation of a $5^{\prime}$ upstream regulatory sequence in the human tyrosinase gene homologous to the locus control region of the mouse tyrosinase gene. Pigment Cell Res 16, 685-692

62. Riley PA (1999) The great DOPA mystery: The source and significance of DOPA in phase I melanogenesis. Cell Mol Biol 45, 951-960

63. Rinchik EM, Stoye JP, Frankel WN, Coffin J, Kwon BS, et al. (1993) Molecular analysis of viable spontaneous and radiation-induced albino (c)-locus mutations in the mouse. Mutat Res 286, 199-207

64. Rinchik E, Bell J, Hunsicker P, Friedman J, Jackson I, et al. (1994) Molecular genetics of the brown (b)-locus region of mouse chromosome 4. I. Origin and molecular mapping of radiation-and chemical-induced lethal brown deletions. Genetics 137, 845-854

65. Ruppert S, Müller G, Kwon B, Schütz G (1988) Multiple transcripts of the mouse tyrosinase gene are generated by alternative splicing. EMBO J 7, 27152722

66. Russell E (1948) A quantitative histological study of the pigment found in the coat color mutants of the house mouse. 2. Estimates of the total volume of pigment. Genetics 33, 228-236

67. Russell L, Montgomery C, Raymer G (1982) Analysis of the albino-locus region of the mouse: IV. Characterization of 34 deficiencies. Genetics 100, 427-453

68. Schmidt A, Beermann F (1994) Molecular basis of darkeyed albinism in the mouse. Proc Natl Acad Sci USA $91,4756-4760$

69. Shibahara S, Okinaga S, Tomita Y, Takeda A, Yamamoto $\mathrm{H}$, et al. (1990) A point mutation in the tyrosinase gene of BALB/c albino mouse causing the 
cysteine-serine substitution at position 85. Eur J Biochem 189, 455-461

70. Silvers WK (1979) The coat colors of mice-a model for mammalian gene action and interaction (New York: Springer)

71. Simmen T, Schmidt A, Hunziker W, Beermann F (1999) The tyrosinase tail mediates sorting to the lysosomal compartment in MDCK cells via a di-leucine and a tyrosine-based signal. J Cell Sci 112, 45-53

72. Sweet H (1987) Acromelanic $\left(c^{a}\right)$. Mouse News Lett 78, 56

73. Takeuchi S, Takeuchi T, Yamamoto H (2000) A possible mechanism for feedback regulation of the mouse tyrosinase gene by its $3^{\prime}$ non-coding RNA fragments. Pigment Cell Res 13, 109-115

74. Townsend D, Witkop CJ, Mattson J (1981) Tyrosinase subcellular distribution and kinetic parameters in wild type and C-locus mutant C57BL/6J mice. J Exp Zool 216, 113-119

75. Townsend D, Guillery P, King R (1985) Himalayan tyrosinase does not demonstrate temperature sensitivity. In: Bagnara J, Klaus S, Paul E, Schartel M. eds Biological, Molecular and Clinical Aspects of Pig- mentation (Tokyo: University of Tokyo Press)

76. Toyofuku K, Wada I, Valencia J, Kushimoto T, Ferrans V, et al. (2001) Oculocutaneous albinism types 1 and 3 are ER retention diseases: mutation of tyrosinase or Tyrp1 can affect the processing of both mutant and wild-type proteins. FASEB J 15, 2149-2161

77. Wakamatsu K, Ito S (2002) Advanced chemical methods in melanin determination. Pigment Cell Res 15, 174-183

78. Widlund H, Fisher D (2003) Microphthalmia-associated transcription factor: a critical regulator of pigment cell development and survival. Oncogene 22, 30353041

79. Wu M, Rinchik EM, Wilkinson E, Johnson DK (1997) Inherited somatic mosaicism caused by an intracisternal particle insertion in the mouse tyrosinase gene. Proc Natl Acad Sci USA 94, 890894

80. Yokoyama T, Silversides DW, Waymire KG, Kwon BS, Takeuchi T, et al. (1990) Conserved cysteine to serine mutation in tyrosinase is responsible for the classical albino mutation in laboratory mice. Nucleic Acids Res $18,7293-7298$ 